\title{
Materials and Additive Manufacturing for Energy Efficiency in Wind Turbine and Aircraft Industries
}

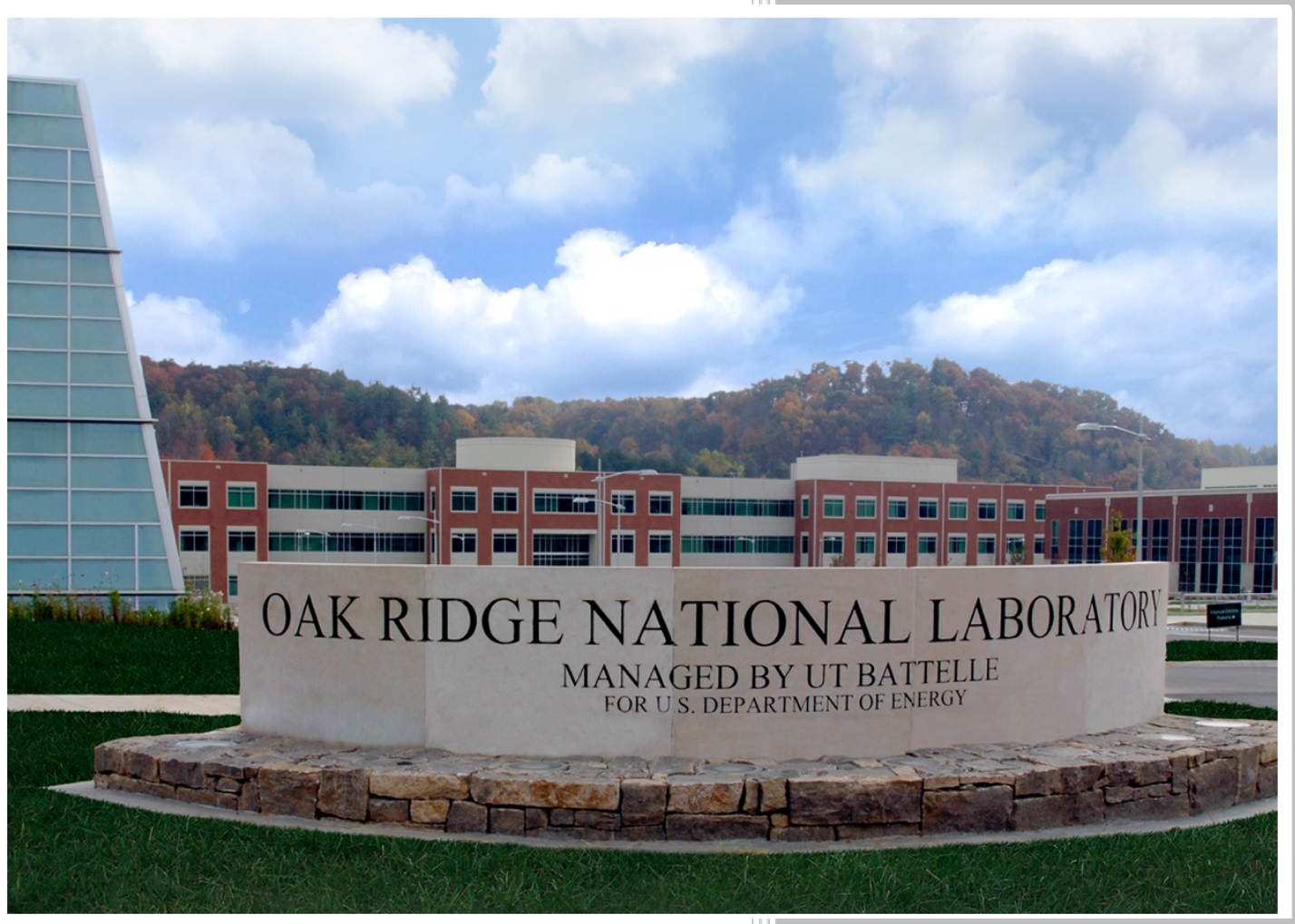

Panos Datskos, ORNL

CRADA FINAL REPORT NFE-15-05571

Approved for Public Release. Distribution is Unlimited.

May 4, 2016 


\title{
DOCUMENT AVAILABILITY
}

Reports produced after January 1, 1996, are generally available free via US Department of Energy (DOE) SciTech Connect.

Website http://www.osti.gov/scitech/

Reports produced before January 1, 1996, may be purchased by members of the public from the following source:

\author{
National Technical Information Service \\ 5285 Port Royal Road \\ Springfield, VA 22161 \\ Telephone 703-605-6000 (1-800-553-6847) \\ TDD 703-487-4639 \\ Fax 703-605-6900 \\ E-mail info@ntis.gov \\ Website http://www.ntis.gov/help/ordermethods.aspx
}

Reports are available to DOE employees, DOE contractors, Energy Technology Data Exchange representatives, and International Nuclear Information System representatives from the following source:

Office of Scientific and Technical Information

PO Box 62

Oak Ridge, TN 37831

Telephone 865-576-8401

Fax 865-576-5728

E-mail reports@osti.gov

Website http://www.osti.gov/contact.html

This report was prepared as an account of work sponsored by an agency of the United States Government. Neither the United States Government nor any agency thereof, nor any of their employees, makes any warranty, express or implied, or assumes any legal liability or responsibility for the accuracy, completeness, or usefulness of any information, apparatus, product, or process disclosed, or represents that its use would not infringe privately owned rights. Reference herein to any specific commercial product, process, or service by trade name, trademark, manufacturer, or otherwise, does not necessarily constitute or imply its endorsement, recommendation, or favoring by the United States Government or any agency thereof. The views and opinions of authors expressed herein do not necessarily state or reflect those of the United States Government or any agency thereof. 
Energy and Transportation Science Division

Advanced Manufacturing Office

\title{
Materials and Additive Manufacturing for Energy Efficiency in Wind Turbine and
} Aircraft Industries

\author{
Panos Datskos, ORNL \\ Georgios Polyzos, ORNL \\ Art Clemons, ORNL \\ Paul Bolton, Piedmont Propulsion Systems, LLC \\ Aaron Hollander, First Aviation Services Inc.
}

Date Published:

May 4, 2016

\author{
Prepared by \\ OAK RIDGE NATIONAL LABORATORY \\ Oak Ridge, Tennessee 37831-6283 \\ managed by \\ UT-BATTELLE, LLC \\ for the \\ US DEPARTMENT OF ENERGY \\ under contract DE-AC05-00OR22725
}

Approved For Public Release 


\section{CONTENTS}

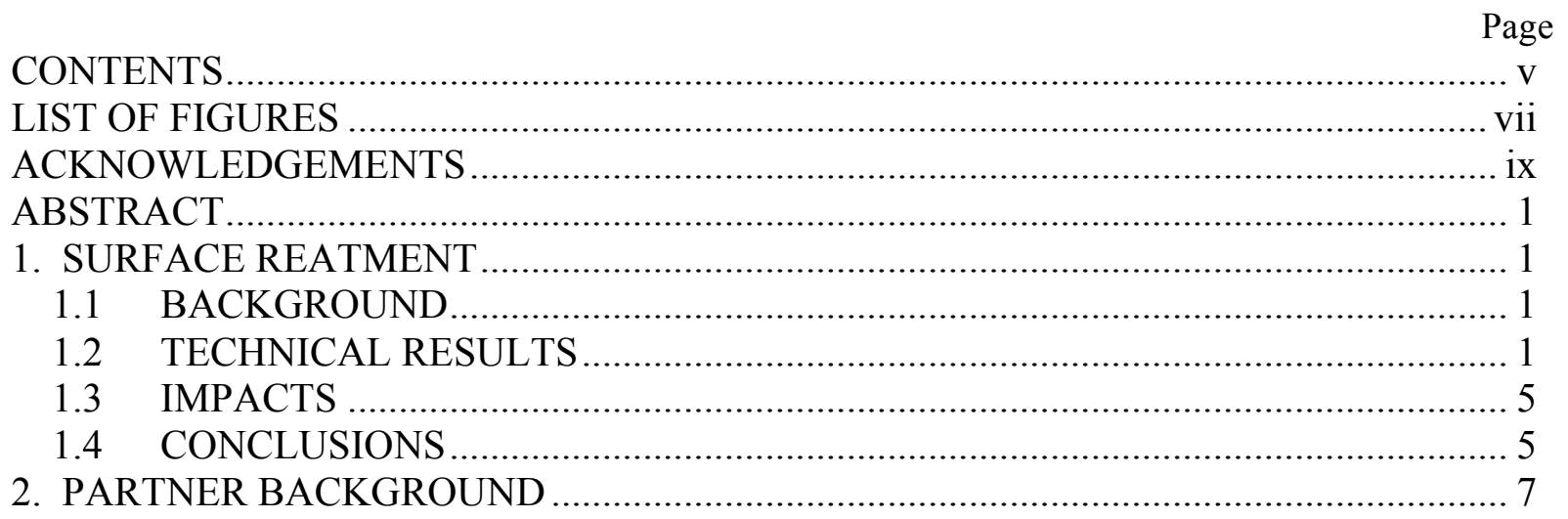




\section{LIST OF FIGURES}

Fig. 1. Surface treated tapes with SH particles of different sizes and geometries.

Fig. 2. SEM images of the particles used to coat the tapes: (a) cylindrical DE, (b) circular DE, and (c) spherical silica particles.

Fig. 3. (a) Taber abrader instrument that was used to perform the surface abrasion measurements. (b)

Coating thickness as a function of abrasion cycles.

Fig. 4. (a) and (b) Aircraft propeller coated with SH particles. The water droplets roll off the propeller's surface.

Fig. 5. (a) Optical microscopy image of a patterned polymer film using plasma-etching techniques.

(b) Polymer film volumetrically filled with SH particles. The diameter is approximately 3 inches...... 4

Fig. 6. Example applications of anti-icing superhydrophobic films............................................... 5 


\section{ACKNOWLEDGEMENTS}

This CRADA NFE-15-05571 was conducted as a Technical Collaboration project within the Oak Ridge National Laboratory (ORNL) Manufacturing Demonstration Facility (MDF) sponsored by the US Department of Energy Advanced Manufacturing Office (CPS Agreement Number 24761).

Opportunities for MDF technical collaborations are listed in the announcement "Manufacturing Demonstration Facility Technology Collaborations for US Manufacturers in Advanced

Manufacturing and Materials Technologies" posted at http://web.ornl.gov/sci/manufacturing/docs/FBO-ORNL-MDF-2013-2.pdf. The goal of technical collaborations is to engage industry partners to participate in short-term, collaborative projects within the Manufacturing Demonstration Facility (MDF) to assess applicability and of new energy efficient manufacturing technologies. Research sponsored by the U.S. Department of Energy, Office of Energy Efficiency and Renewable Energy, Advanced Manufacturing Office, under contract DE-AC0500OR22725 with UT-Battelle, LLC. 



\begin{abstract}
The purpose of this project was to develop surface treatments which will inhibit the formation of ice on turbine blades and propellers. ORNL worked with Piedmont Propulsion Systems, LLC and First Aviation Services Inc. to demonstrate a new surface treatment for two primary markets, aviation and wind turbines, as well as secondary markets such as power lines, bridges, boats, roofs and antennas among others. Exploring alternative surface treatments for wind turbines will provide antiicing properties and erosion/abrasion prevention properties similar to those for aviation applications. A series of superhydrophobic coating materials was synthesized and successfully applied on anti-ice tape materials that could be used in a wide range of wind turbine and aviation applications to prevent ice accumulation. The coatings developed in this project were based on superhydrophobic particles of different geometries and sizes that were homogeneously dispersed in polymeric binders. The superhydrophobic features of the coatings are volumetric and their abrasion resistance was evaluated. Future research will involve the demonstration of anti-icing properties of the surface treatment developed in this project.
\end{abstract}

\title{
1. SURFACE REATMENT
}

This phase I technical collaboration project (MDF-TC-2015-057) was begun on April 15, 2015 and was completed on April 30, 2016. The collaboration partners Piedmont Propulsion Systems, LLC and First Aviation Services Inc. are small businesses. We have demonstrated the durability of the new surface is comparable with the durability of protective tapes treatment but with the potential for anti-icing behavior.

\subsection{BACKGROUND}

Piedmont Propulsion Systems, LLC is incorporated in North Carolina and employs a staff of approximately 45 and offer extensive component maintenance and overhaul capability for the commercial, regional, corporate and general aviation industry. First Aviation Services Inc. is located in Westport, Connecticut and is leading provider of repair and overhaul, rotables management and related engineering services to the aviation industry worldwide.

Aviation and wind turbine blade efficiency degrades rapidly with any change in airfoil shape, whether caused by accretion of ice or other substances, or due to erosion, abrasion or other impact. Furthermore, ice and snow accumulation often requires that wind turbines be shut down in order to avoid mechanical loads in excess of design limits; of course, repairs to blade erosion or impact damage require the units to be shut down immediately, as well.

The objective of this project was to develop and optimize the durability and formulation of antiice coatings with volumetric features which can be applied on polymer tapes. The coatings can be easily applied on large surface area wind turbine blades and propellers as well as other aerodynamically exposed surfaces using conventional application techniques. The resulting surface treatment is anticipated to enhance the wear and anti-ice resistance of current technology coatings.

\subsection{TECHNICAL RESULTS}

Nanostructured silica-based particles of different geometries and sizes were functionalized with fluorosilanes. The functionalization procedure was performed according to previous studies at ORNL (G. Polizos, K. Winter, M.J. Lance, H.M. Meyer, B.L. Armstrong, D.A. Schaeffer, J.T. Simpson, S.R. 
Hunter, P.G. Datskos, Appl. Surf. Sci. 292, 563-569, 2014). Tape strips were spray-coated with suspensions of superhydrophobic (SH) particles, polymer binder and solvent. Several formulations based on different particle sizes and particle geometries were used in order to establish baseline values for the performance of the tapes. Typical examples of coated tapes are shown in Figure 1.

The tapes were coated using a two-step process:

(1) A binder layer (Kiltz) was applied on the tapes and allowed to dry for 20 minutes.

(2) A suspension of superhydrophobic particulates and binder (Clear Coat, CC) in acetone were spray deposited on top of the tapes. The polymer binders used in this set of samples are commercially available. The particle/binder ratio and the particle type varied as shown in Table 1.

Table 1. Sample designation and ratio

\begin{tabular}{|c|c|}
\hline Material & Ratio \\
\hline Polymer binder (Kiltz) & 1.00 \\
\hline Polymer binder (Clear Coat) & 1.00 \\
\hline Kiltz + SHDE circular $_{\text {(Clear Coat })}$ & 0.85 \\
\hline Kiltz + SHDE cylindrical $_{\text {(Clear Coat }}$ & 0.33 \\
\hline Kiltz + SHDE $_{\text {cylindrical }} /($ Clear Coat $)$ & 0.56 \\
\hline Kiltz + SHDE $/$ SH $_{\text {Spheres }} /($ Clear Coat $)$ & $1 / 1 / 3.33$ \\
\hline Kiltz + SHDE $/$ SH $_{\text {Spheres }} /($ Clear Coat $)$ & $1 / 2 / 5.40$ \\
\hline
\end{tabular}

Scanning electron microscopy images (SEM) of the particles used to coat the tapes are shown in Figure 2. Three different types were used: i) cylindrical diatomaceous earth (DE) particles of approximate size $10 \mu \mathrm{m}$, ii) circular DE particles of approximate size $10 \mu \mathrm{m}$, and iii) spherical silica particles with diameter $600 \mathrm{~nm}$. The spherical particles were synthesized in the lab using sol-gel techniques.

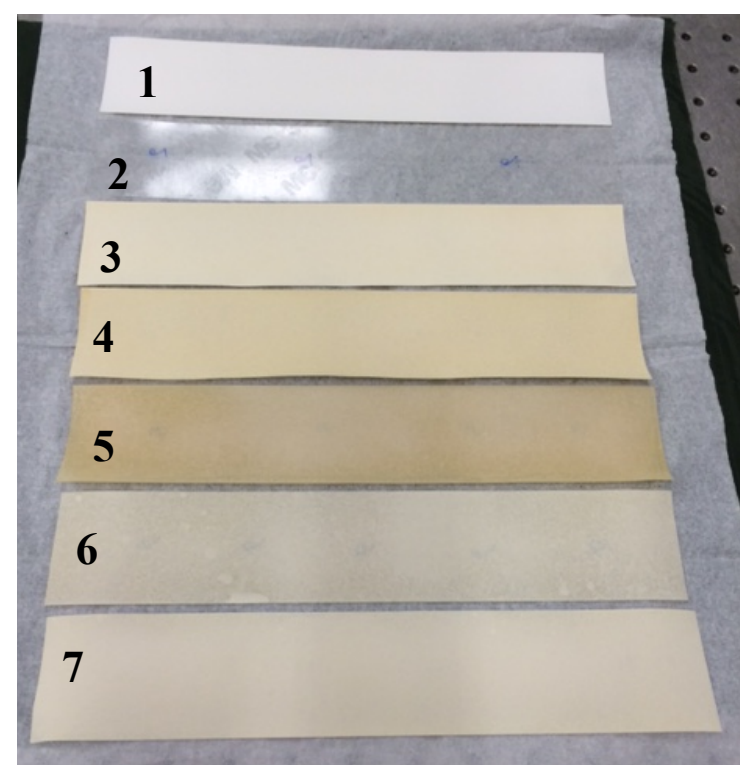

Fig. 1. Surface treated tapes with SH particles of different sizes and geometries. 

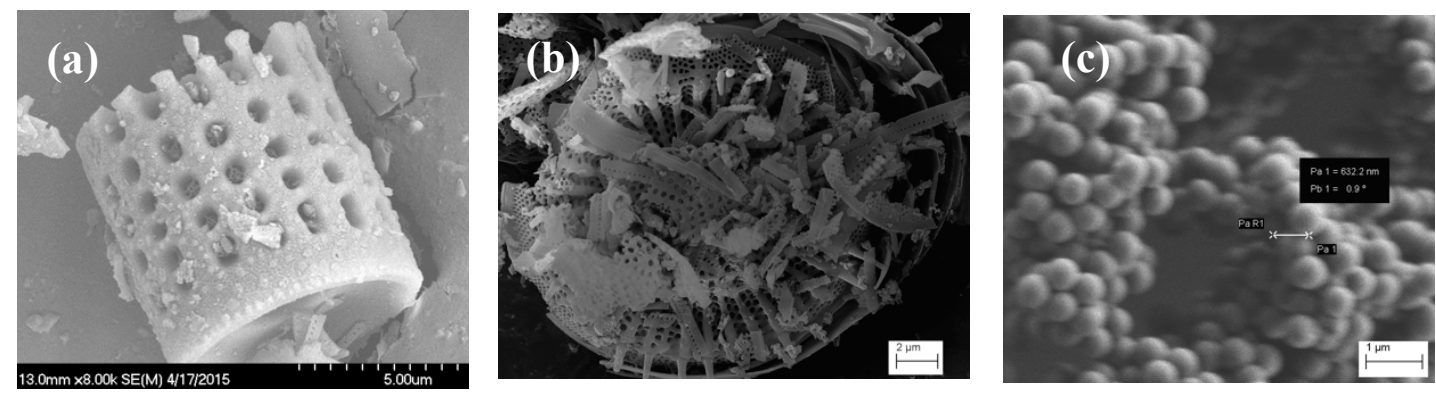

Fig. 2. SEM images of the particles used to coat the tapes: (a) cylindrical DE, (b) circular DE, and (c) spherical silica particles.

The abrasion resistance of this set of samples was tested using the Taber rotary abrasion tester shown in Figure 3a. Two wheels of approximate diameter 2" were rotated over the surface treated samples. The samples were subjected to consecutive abrading cycles and the abraded dust-powder was continuously vacuumed away during the cycles. The Taber abrasion testing was performed according to ASTM D 4060. The surface treated tapes were superhydrophobic with a water contact angle greater than 150 degrees. The non-coated tapes had a water contact angle $\sim 60$ degrees. The samples were abraded against two rough wheels (CS-10) and were subjected to 200 abrading cycles. The abrasion testing results are shown in Figure $3 \mathrm{~b}$ where we plotted the coating thickness as a function of abrading cycles. The abrasion rate of the coated tape was approximately $10 \mu \mathrm{m}$ per 100 cycles, which is higher than the abrasion rate of the non-treated polymer based tape. The durability of the surface treatment for the coated tape sample requires further improvements. We use a similar surface coating to treat a large sample which was an aircraft propeller. The coated aircraft propeller is shown in Figure 4 and exhibited superhydrophobic behavior with a very small roll off angle. Such surface treatments are scalable and can be applied to large-scale samples.
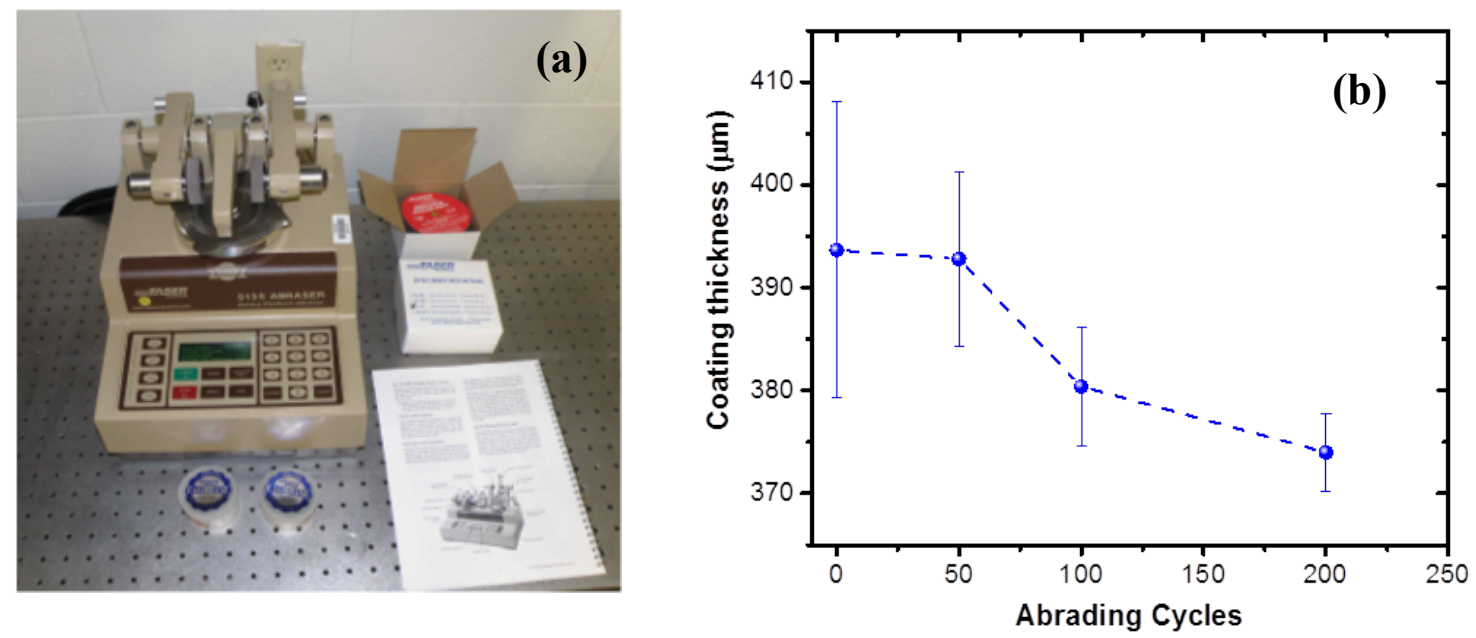

Fig. 3. (a) Taber abrader instrument that was used to perform the surface abrasion measurements. (b) Coating thickness as a function of abrasion cycles. 

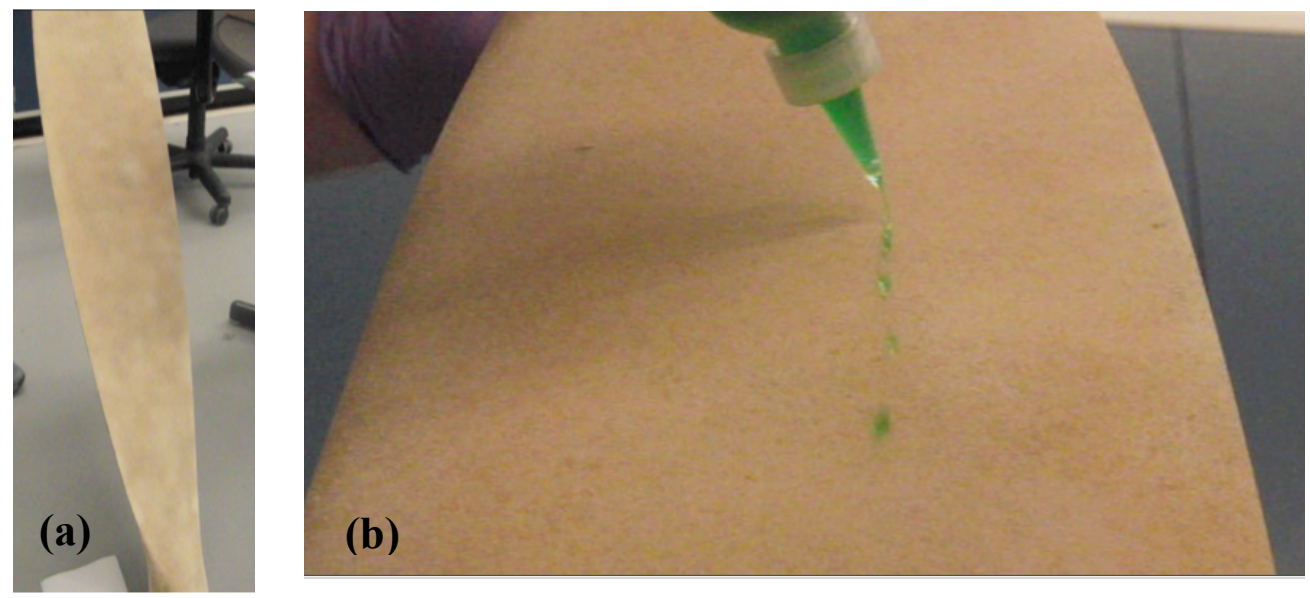

Fig. 4. (a) and (b) Aircraft propeller coated with SH particles. The water droplets roll off the propeller's surface.

In order to enhance the wear resistance of the treated tapes, a second approach was pursued. Polymer films were volumetrically filled with SH particles and their surface was patterned using plasma-etching techniques. The plasma etch conditions were optimized (see Table 2). We used a mixture of $\mathrm{CF}_{4}(90 \mathrm{sccm})$ and $\mathrm{O}_{2}(45 \mathrm{sccm})$ gasses. The pressure in the chamber was $600 \mathrm{mTorr}$ and the power $500 \mathrm{~W}$. Samples were etched for 30 minutes. Representative images of the films are shown in Figure 5. The polymer films were found to have abrasion resistance properties that are comparable to the respective properties of the pristine polymer films. The SH nanostructured films must be scaled up in order to evaluate their anti-icing properties.

Table 2. Plasma etching conditions

\begin{tabular}{|l|l|}
\hline Plasma gases & $\mathrm{CF}_{4}: \mathrm{O}_{2}(90 \mathrm{sccm}: 45 \mathrm{sccm})$ \\
\hline Pressure & 600 mTorr \\
\hline Power & $500 \mathrm{~W}$ \\
\hline Etching tome & 30 minutes \\
\hline
\end{tabular}
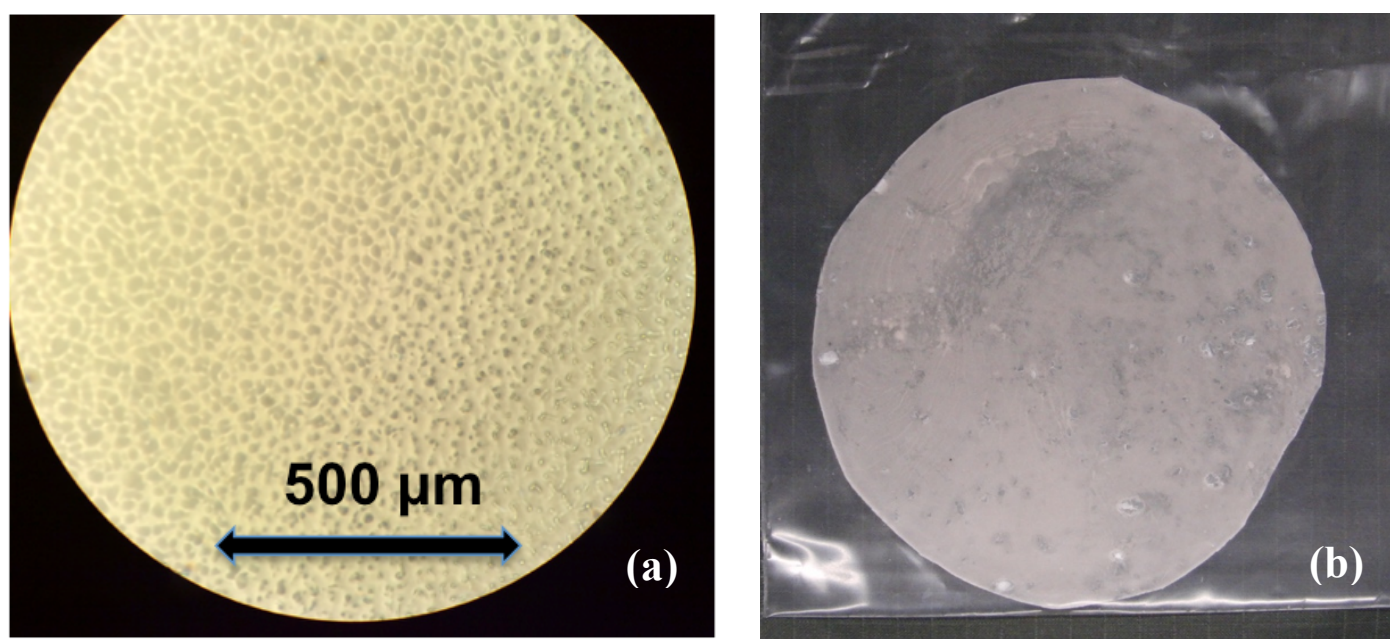

Fig. 5. (a) Optical microscopy image of a patterned polymer film using plasmaetching techniques. (b) Polymer film volumetrically filled with SH particles. The diameter is approximately 3 inches. 


\subsection{IMPACTS}

The collaboration between First Aviation Services Inc. (parent company to Piedmont Propulsion Systems, LLC) and the Oak Ridge National Laboratory (ORNL) was to develop a surface treatment which reduces icing and erosion risks for two primary markets, aviation (both rotary- and fixed-wing aircraft) and wind turbines, as well as multiple secondary markets such as power lines, bridges, boats, roofs and antennas, among others. The surface treatment must have at least two important properties to be useful:

1. Anti-ice -- to prevent ice formation on surfaces; and

2. Wear Resistant-- high erosion and abrasion resistance to extend useful life of the surface.

Future research will involve the study of the surface treatment to be used in conjunction with other conventional anti-ice methodologies as well as for inspection purposes.

This effort enabled Piedmont Propulsion Systems, LLC and First Aviation Services access to the ORNL Manufacturing Demonstration Facility (MDF) and other unique facilities and technical expertise in advanced materials and manufacturing.

Upon successful demonstration of the anti-icing properties, the developed films can be utilized to coat polymer tapes that are currently used to reduce the ice accumulation in rotary components such us propellers and wind turbine blades.

\subsection{CONCLUSIONS}

Nanostructured films with volumetric superhydrophobic properties were fabricated using two approaches. The best performing films have abrasion resistance properties compared to the abrasion resistance of the pristine films. The anti-icing properties of the films must be evaluated in order to assess their potential use as anti-icing tapes for wind turbine blades and propellers. The developed coatings can be applied to large-scale infrastructure.

Additional studies are required to scale up and evaluate the anti-icing performance of the coatings based on the plasma etching techniques. The dependence between the ice formation and the size of the surface features, as well as the lifetime of the coatings, should be investigated further.
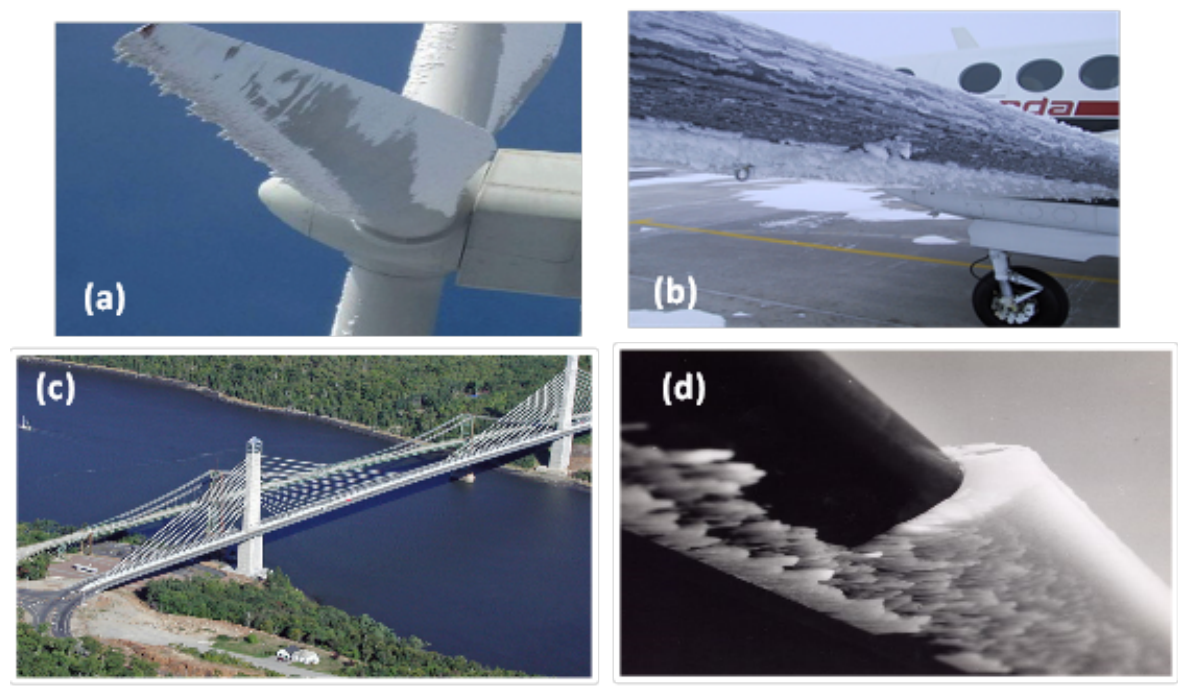

Fig. 6. Example applications of anti-icing superhydrophobic films. 


\section{PARTNER BACKGROUND}

Piedmont Propulsion Systems, LLC offers extensive component maintenance and overhaul capability for the commercial, regional, corporate and general aviation industry. Our facilities are located in North Carolina, with regional sales representatives worldwide. Piedmont is a FAA and EASA Part 145 Repair Station with nearly 60 years of experience in propeller maintenance and overhauls.

First Aviation Services Inc. ("FAvS"), is located in Westport, Connecticut, and is a leading provider of repair and overhaul, rotables management and related engineering services to the aviation industry worldwide. FAvS's principal operating subsidiaries are Aerospace Turbine Rotables, Inc. ("AeTR") located in Wichita, Kansas and Addison, Texas, Evōlution Aerospace, Inc. in Wichita, Kansas and Piedmont Propulsion Systems, LLC ("PPS") in Winston-Salem, North Carolina. FAvS was established in June 1995 by First Equity Group ("First Equity") to acquire National Airmotive Corporation ("NAC") from Triton Group Ltd. In March 1997, First Aviation subsequently acquired the assets of Aerospace Products International, Inc. ("API" - formerly Aircraft Parts International Combs, Inc.) from AMR Combs, Inc., a subsidiary of AMR. 